\title{
Analysis on the Construction and Management of High-Tech Characteristic Towns in Hangzhou
}

\section{-Based on the Research of Hangzhou Dream Town}

\author{
Yifeng Chen ${ }^{1}$, Songyan Zhang1 ${ }^{*}$, Heyi Fu ${ }^{2}$ \\ ${ }^{1}$ School of Economics and Management, Zhejiang University of Science and Technology, Hangzhou, China \\ ${ }^{2}$ School of Sciences, Zhejiang University of Science and Technology, Hangzhou, China \\ Email: *syzh201@163.com
}

How to cite this paper: Chen, Y.F., Zhang, S.Y. and Fu, H.Y. (2019) Analysis on the Construction and Management of High-Tech Characteristic Towns in Hangzhou. Open Journal of Social Sciences, 7, 397-405. https://doi.org/10.4236/jss.2019.710034

Received: October 18, 2019 Accepted: October 28, 2019 Published: October 31, 2019

\begin{abstract}
The characteristic town is an innovative new economic development model to explore the integration of industry and city, and a practice to promote the supply-side structural reform in Zhejiang. This paper analyzes the construction status and social satisfaction of dream town in Hangzhou, explores the economic operation system of high-tech characteristic town, summarizes the difficulties encountered in the construction process, and summarizes the economic development model of universal significance.
\end{abstract}

\section{Keywords}

Characteristic Town, High and New Technology, City Integration Production

\section{Introduction}

Featured small towns are a new model of innovative economic development that integrates "production, city, people and culture". They are a major initiative of Zhejiang and a practice of promoting supply-side structural reform in Zhejiang. High-tech featured town is a featured town with high-tech as the guide, high-end industry as the core, high-level talents as the driving force, innovation chain and industrial chain organic integration. The characteristic town is the result of the collision of characteristic industry and industry city, and it is an important measure to break the bottleneck of resources and improve the living environment. With Internet entrepreneurship and venture capital as its industry positioning, Hangzhou dream town gathers a large number of enterprises and entrepreneurial talents, and obtains a large number of entrepreneurial projects and project financing. It is a national Internet innovation and entrepreneurship 
industry highland and was listed in the first batch of Zhejiang provincial special towns in October 2016. What are the demands of different interest groups on the construction of dream town in the past five years? How to make use of the higher quality development of the characteristic town model? Through the analysis of the social satisfaction of this characteristic town, we can understand the construction performance of the town, explore the economic operation system of the characteristic town, summarize the difficulties encountered in the construction process, and summarize the road of economic development model with universal significance, so as to help other high-tech characteristic towns develop in high quality.

\section{Construction Status of Dream Town in Hangzhou}

\subsection{Complete Supporting Facilities Plural Development}

Located in the core area of the future science and technology city and the science and innovation corridor in the west of the city, the dream town has an overall planning area of about 3 square kilometers. With the industry orientation of Internet entrepreneurship and venture capital, it has gathered a large number of Internet enterprises and excellent innovative and entrepreneurial talents, and obtained a large number of high-quality projects and project financing [1]. Around the "Internet + business" and "Internet + finance" leading industries, and planning of the Internet, angel village, bazaars and four core business street blocks, belong to high and new technical characteristic town, dream town rely on high-end technology agglomeration advantages, "to the point with surface" form "seed storehouse, incubator, accelerator, industrial park" industrial supporting close multivariate stereoscopic development new pattern.

\subsection{Gather the "New Fourth Army" to Build Advantages in Mass Entrepreneurship and Innovation}

Dream town gathers "new fourth army" of entrepreneurship represented by "Ali department, Zhejiang university department, overseas returnees department and Zhejiang business department", and becomes the national Internet entrepreneurship and innovation highland [2]. Based on the principle of gathering good ideas and projects related to the Internet industry, it has gathered 12,900 entrepreneurship talents and 1341 Internet entrepreneurship projects. Among them, 136 projects have received more than one million yuan of financing, with the amount of financing exceeding 9.425 billion yuan. More than 1000 technology finance and Internet finance companies have gathered angel investment funds, equity investment institutions and wealth management institutions to take root in dream town, with more than 263 billion yuan of managed capital.

\section{Empirical Study on Social Satisfaction of Dream Town}

\subsection{Research Background}

As one of the first featured small towns in Zhejiang province and the first 
high-tech featured small towns in Zhejiang province, dream town has become the core block of incubation platform for future science and technology city and concentration of equity investment institutions after more than 5 years of practice. The purpose of this project is to better explore the different demands of different stakeholders on the construction of dream town, understand the social satisfaction situation since the planning and construction of dream town, and put forward Suggestions for its shortcomings.

This research adopts the field sampling, in the form of the dream of town residents, employees and visitors, the questionnaire survey to different stakeholders in order to ensure the authenticity of the questionnaire survey and targeted, below involved all research number according to the number of effective to fill in the questionnaire, or 356 people, 188 men and 168 women, $5.61 \%$ than under the age of 20,20 to 30 years of age accounted for $60.67 \%, 33.14 \%$ than 30 to 60 years old, 60 , more than $0.58 \%$.

\subsection{Regression Model Construction and Fitting Degree Analysis of Satisfaction Degree of Dream Town Construction}

In order to construct a regression model of satisfaction in town construction, we conducted a survey and Analysis on the satisfaction of tourists and local residents. Both the number of tourists and local residents surveyed and the impact accounted for 50\%. According to the influencing factors of the satisfaction of the questionnaire, we analyze the questions of the questionnaire, select 16 influencing factors, and assign 5 to 1 points to the satisfaction, comparative satisfaction, general, dissatisfaction and very dissatisfaction of the 16 factors. After the assignment, KMO and Bartlett spherical test are carried out. The results are as Table 1 .

According to the above tests, it shows that factor analysis is suitable for analysis. In order to identify the factors with significant impact, we analyzed the correlation of 16 factors. After analysis, only 14 factors had significant impact on satisfaction. According to its significance level, we summarize the influencing factors into four influential factors: location $x_{1}$, environment $x_{2}$, service $x_{3}$, town management mode understanding and recognition $x_{4}$. (For example, for location satisfaction, the influence factor can be obtained from the analysis from three questions in the questionnaire: are you satisfied with the location of the dream town, are you satisfied with the traffic convenience around the dream town, and are you satisfied with the parking around the dream town?)

Table 1. KMO and Bartlett spherical test.

\begin{tabular}{lcc}
\hline \multicolumn{2}{c}{ Sample enough KMO measures } & 0.889 \\
\hline Bartlett spherical test & Approximate chi-square & 143.322 \\
& D & 28 \\
& Sid & 0.000
\end{tabular}


In order to get the relationship between these four influencing factors and town satisfaction, we will use multiple linear regression method, and take the four variables location $x_{1}$, environment $x_{2}$, service $x_{3}$, town management mode understanding and recognition $X_{4}$ as independent variables to conduct linear regression.

From Table 2, we can see that the regression coefficient is $\beta_{1}=-0.632, \beta_{2}=$ $0.691, \beta_{3}=0.676, \beta_{4}=0.518$. So the multiple linear regression equation established with the satisfaction of small town FM as the dependent variable, the satisfaction of location $x_{1}$, the satisfaction of environment $x_{2}$, the satisfaction of service $x_{3}$, the satisfaction of understanding and identification of small town management mode $x_{4}$ as the independent variable is as follows:

$$
F_{m}=0.632 x_{1}+0.691 x_{2}+0.676 x_{3}+0.518 x_{4}+1.71
$$

From the regression equation, we can see that the social satisfaction of dream town construction is positively related to the location satisfaction, environmental satisfaction, service satisfaction, understanding of town management mode and satisfaction of recognition degree. It can be seen from Table 3 that $R^{2}=$ 0909, indicating that the fitting result is very good. It can be seen from Table 4 that $F=15.921, F_{0.05} \geq 2.21$, corresponding $p$ value is $0.00<0.05$, so regression equation can be considered significant.

Table 2. Regression coefficient of social satisfaction of dream town.

\begin{tabular}{|c|c|c|c|c|c|}
\hline \multirow[t]{2}{*}{ Model } & \multicolumn{2}{|c|}{$\begin{array}{l}\text { Regression } \\
\text { coefficients }\end{array}$} & \multirow{2}{*}{$\begin{array}{c}\text { Regression } \\
\text { coefficients } \\
\text { Beta }\end{array}$} & \multirow[t]{2}{*}{$\mathrm{t}$} & \multirow[t]{2}{*}{ Sig. } \\
\hline & $\mathrm{B}$ & Std. Error & & & \\
\hline Constant & 1.71 & 0.135 & & 2.983 & 0.008 \\
\hline Location $x_{1}$ & 0.632 & 0.095 & 0.721 & 4.625 & 0.000 \\
\hline Environment $x_{2}$ & 0.691 & 0.01 & 0.0766 & 6.923 & 0.0209 \\
\hline Service $x_{3}$ & 0.676 & 0.016 & 0.835 & 5.228 & 0.000 \\
\hline $\begin{array}{l}\text { Understanding and recognition } \\
\text { of management mode } x_{4}\end{array}$ & 0.518 & 0.031 & 0.622 & 1.327 & 0.052 \\
\hline
\end{tabular}

Table 3. Fitting test of regression model equation of social satisfaction.

\begin{tabular}{ccccc}
\hline $\mathrm{R}$ & R Square & Adjusted R Square & Std. Error of Estimate & Dubbin Watson \\
\hline 0.952 & 0.909 & 0.901 & 0.4728 & 679.532 \\
\hline
\end{tabular}

Table 4. Significance test of regression model equation ( $F$ test).

\begin{tabular}{cccccc}
\hline & Sum of Squares & D & Mean Square & F & Sig. \\
\hline Regression & 678.587 & 5 & 362.661 & 15.921 & 0.00 \\
Residual & 729.758 & 20 & 211.336 & & \\
Total & 578.230 & 25 & & \\
\hline
\end{tabular}




\subsection{Survey and Summary of Social Satisfaction in Dream Town}

Through regression analysis, it can be found that the location, environment and service of the town have a significant impact on the satisfaction of the town [3]. Residents/employees are satisfied with the location of the featured town. The dream town is located in the future science and technology city of Hangzhou. Dream town ancient architectural style, good town environment attracted many visitors.

On the other hand through the tourist town feel this part of the problem in the questionnaire we found that the visitors to the characteristics of town where most critical is the service, town staff hospitality services are not professional, at the same time, the small town of reception has limit to the size of the tour group, small town does not receive 50 the following tour group, which caused a lot of tourists, thus town needs to raise the service level, should not limit the number of interpretation of the group at the same time, in order to improve tourist satisfaction. The level of goods in Hangzhou is high, so residents/employees hope the relevant enterprises in the characteristic town can raise their salary level to improve their satisfaction.

In addition, the infrastructure of dream town is still not perfect, the resources of education and medical treatment are relatively limited, there are few parking Spaces near the town, and parking is difficult, so the residents/employees hope that the infrastructure of dream town can bring improvement [4]. The development of high-tech characteristic towns should not only develop high technology, but also develop diversified culture and give cultural connotation to the towns. In order to retain talents, improve infrastructure and improve service management level for the development of dream town's future construction, it is of vital importance to the well-being of residents, employees, employees and other groups with different interests.

\section{Main Problems of Dream Town}

According to the field research of the research group and the empirical study of social satisfaction, it can be seen that dream town has the following series of problems.

\subsection{Small Town Enterprises Attract Investment Difficult, High Financing Costs}

Under the leadership of the government, dream town is featured by high-tech innovation jointly promoted by enterprises and scientific research institutes[5].In the short term, good results have been achieved, the number of artificial intelligence enterprises has greatly improved. However, the number of start-up financing projects in dream town has declined in the past five years, according to the monitoring data of Wisdom for cloud. Even if the local government to win the project presents a great preferential policies and high tolerance, however, support the development of artificial intelligence capital mainly comes 
from the town, the industrial fund, risk investment policy, capital etc., there are many related enterprises in pursuit of short-term economic benefit, cannot be engaged in cutting-edge technology research and development, led to the development of fatigue.

\subsection{The Enterprise Is Not Stable and Lacks Policy Binding Force}

"Public entrepreneurship, peoples innovation" the popularity of ideological trend, a growing number of startups landing dream town, this brought good double gen atmosphere for dream town, many small and medium-sized enterprise partnership entrepreneurship, however, tend to be small, money does not reach the designated position, lack of experience, the system is not sound, conflict resolution mechanism also is relatively single, which makes the stability of the enterprise is not strong, the characteristics of the liquid, easy to form town in waste of resources, destruction of business ecosystem stability.

\subsection{The Mechanism for Training High-End Talents Is Not Perfect, and the Supply and Demand of Talents Are Structurally Unbalanced}

High-tech enterprises need a large number of talents with advanced degrees. However, according to the number of universities distributed in 211/985, There are 26 in Beijing, 10 in Shanghai and only one in Hangzhou. As traditional centers of higher education, Beijing and Shanghai have strong foundations, while Hangzhou relies heavily on graduates from foreign universities, which is one reason for the shortage of high-end talents in dream town [6]. In addition, there is a small supply of high-end compound talents who know emerging technologies such as artificial intelligence, big data and intelligent communication, which leads to the slow talent cultivation in dream town and the imbalance between supply and demand of highly sophisticated talents.

\subsection{Low Industrial Science and Technology Content, Lack of Prominent Key Industries}

In the process of the construction of characteristic towns, local governments should adhere to the value pursuit of craftsman spirit, highlight the "characteristics" of characteristic towns and make full use of and consolidate the connotation of characteristic towns. Although dream town is established with high and new technology and has made great achievements in the field of artificial intelligence such as Internet, big data and cloud computing, only some Ali enterprises are rich in high technology, and many start-ups are still at the level of service outsourcing with low technology content. At the same time, the phenomenon of big fish eating small fish is serious. Many leading enterprises have accumulated a series of technological achievements, but other small and medium-sized enterprises are exploring in the form of dots. However, how to integrate organically with the Internet, big data and cloud computing has not yet explored an effective business model. 


\section{Thinking on Promoting the Management and Construction of High-Tech Characteristic Towns}

Faced with a series of problems in characteristic towns, it is urgent to make innovative responses from four dimensions, including talent training, investment attraction, industrial planning and service management.

\subsection{Forming a Three-In-One Personnel Training System for Small-Town Enterprises and Colleges}

For industrial technology content is low, the lack of talent, dream town to associated enterprises and the bridge and link role of colleges and universities, by supporting facilities to attract talent and enterprise, the second need to be "teaching into the enterprise", encourage colleges and universities, introduced the enterprise resources [7], the enterprise has ability of algorithm and computing resources combined with the data supply, accelerate the artificial intelligence, colleges and universities, enterprises and research institutes to develop artificial intelligence discipline construction, talents to make faster to master the professional skills required to artificial intelligence industry, faster into industrial practice, alleviate the "labor shortage" problem of artificial intelligence industry.

\subsection{Give Play to the Financing Mode Guided by the Government to Attract Investment around the Industrial Chain}

We will increase financial support for basic frontier research, the space for crowd innovation, the development of open platforms, and demonstration of innovative applications. Focusing on the investment attraction of the industrial chain, the government actively applies the model of cooperation between the government and social capital, the government gives play to the guidance of industrial fund, enterprises coordinate with each other, and attracts social capital to set up related sub-funds[8].Cross-regional open layout of the industrial chain, according to the industrial chain investment, in order to avoid each characteristic town competing for limited resources, can focus on the local dominant industrial chain investment. Give full play to the inherent conditions of angel village, and form a series of industrial chain supporting services, including settlement service, angel investment, capital intermediary, fund raising and business coordination.

\subsection{Seizing Industrial Development Opportunities and Accelerating the Development of Artificial Intelligence}

Future dream town is located in the Hangzhou science and technology city and Core area of science and technology innovation corridor in the west of the city has a good industry and technology base, to seize opportunities for development, promote the transfer of scientific and technological achievements transformation, the formation of agglomeration good entrepreneurial hub of all kinds of resources, support to build the town enterprise to strengthen the patent layout, 
participate in international standards, giving full play to the advantages of Zhejiang industry in the field of Internet economy [9], the cloud computing, big data, speech recognition, image recognition, intelligent robots, virtual reality and other new areas to speed up cultivating a batch of leading enterprises, and encourage small and medium-sized enterprise intelligent development.

\subsection{Explore New Ways to Integrate Industries with Cities and Accelerate the Transformation of Government Service System}

Government according to the requirements of "the bartender", accelerate the transformation of administrative service concept and service system, strengthen the supporting from several aspects, in education, health care, administration, service, actively implement the network, parking and other aspects, make with affinity to the development of the environment, the government policy of environmental protection, land intensive management[10], multiple dimensions such as the integration of policies of government management system running system, ensure scientific decision-making, to explore the optimal path of city integration.

\section{Acknowledgements}

This work was supported by 2017 University Students of Zhejiang Science and Technology Innovation Activity Fund (New Talent Program) (2017R415003).

\section{Conflicts of Interest}

The authors declare no conflicts of interest regarding the publication of this paper.

\section{References}

[1] Zhu, Y.Y. (2016) Current Situation and Countermeasures of the Construction of Characteristic Towns in Zhejiang Province: A Case Study of Jiaxing City. Journal of Jiaxing University, 28, 49-56.

[2] Cao, K. and Liu, M.L. (2019) Research on the Development Mechanism of Featured Towns from the Perspective of Space Production: A Case Study of Hangzhou Dream Town. Modern City Research, 5, 25-29.

[3] Gao, X.Y. (2018) Can and How Can Real Estate Enterprises Participate in the Construction of Characteristic Towns. Zhejiang University, Hangzhou, 1-40.

[4] Li, S.Y. and Liu, Q.H. (2018) Research on Functional Positioning of Featured Towns from the Perspective of Industry-City Integration: A Case Study of Taiping Town in Nanchang. Urban Development Research, 25, 168-172.

[5] Zeng, J. and Ci, F. (2016) Construction of Characteristic Towns under the Background of New Urbanization. Macroeconomic Management, 12, 51-56.

[6] Zhong, Z.M. and Li, Z.M. (2018) Analysis on the Construction and Management of High-Tech Featured Towns: Based on the Observation of Xiuzhou Intelligent Logistics Town. Knowledge Economy, 10, 16-17.

[7] Wu, J.H. (2019) A Study on the Training Path of Entrepreneurship and Innovation Talents from the Perspective of Small Towns with Chinese Characteristics: A Case 
Study of IT Town in Foshan High-Tech Zone. China External Education, 3, 26-27.

[8] Xie, W.W. and Zhu, Z.G. (2016) System and Policy Innovation of Characteristic Town Establishment: A Case Study of Yuhuangshan Nanji Town. Zhejiang Finance, 9, 69-74.

[9] Li, M.Y. (2018) Research on the Integration Degree of Characteristic Towns. Jiangxi University of Science and Technology, Jiangxi, 2-30.

[10] Zhao, X.M. (2019) Network Construction and Mechanism Analysis of Actors in the Innovative Development of Hangzhou Dream Town. Henan University, Henan, $2-25$. 